\title{
Perceptions towards Sustainable Construction amongst Construction Contractors in State of Victoria, Australia
}

\author{
Malik Khalfan, M. Ali Noor, Tayyab Maqsood, Nawaf Alshanbri, and Amrit Sagoo
}

\begin{abstract}
The aim of the paper is to examine the perceptions towards environmental, social and economic benefits of sustainable construction amongst contractors. For this purpose questionnaire survey was employed in two stages with construction contractors in the state of Victoria, Australia. The questionnaire in the first stage focused on the environmental aspects while in the second stage the focus was on the social and economic aspects of sustainable construction. Perceptions towards the social and economic aspects of sustainable construction were positive, with around $60 \%$ of responses demonstrating positive perceptions. Client demand, associated costs of sustainable construction materials and practices and perceptions of employees and workers were perceived as weaknesses towards implementation of sustainable construction practices. The results also showed that some of the drivers of sustainable development and construction were the availability of environmentally friendly (green) material; financial incentives to clients and contractors; government policy for implementation; and overall environmental awareness within the industry. The paper presents an overall perspective of construction contractors and their supply chain towards sustainable construction in the state of Victoria, Australia.
\end{abstract}

Index Terms-Sustainable construction, australia, environmental, economic and social aspects of sustainability, construction contractors, supply chain management.

\section{INTRODUCTION}

The built environment inherently affects and contributes to the way in which we live our lives, including health, safety, and quality of the surrounding environment. The building industry is a primary driver of many economies and has significant contribution towards creation of employment. Globally building in a responsible manner is the need of the hour with consideration to the social, economic and environmental implications is therefore critical to the progress of mankind and the preservation of our planet.

While environmental consciousness was the original driver behind movement towards sustainable design and construction, the concept of sustainability has been expanded to include environmental, social and economic aspects. This concept is known as the 'Three Pillars of Sustainability' or the 'Triple Bottom Line'. The United Nations General Assembly in 1987 defines sustainability as "meeting basic needs of the public and extending opportunities to satisfy their aspirations for a better life without compromising the ability of future generations to meet their own needs".

Manuscript received August 21, 2014; revised October 29, 2014

The authors are with the School of Property, Construction and Project Management, RMIT University (email: malik.khalfan@rmit.edu.au, M.Ali.Noor@hotmail.com, nalshanbri@hotmail.com, Amrit.Sagoo@rmit.edu.au).
The numerous studies conducted have revealed that sustainable construction can have short and long term environmental, social and economic benefits to users, investors, contractors, workers and society as a whole. Market forces, social and economic factors are likely to drive greater demand for sustainability than environmental consciousness and government policy. Awareness of social and economic factors in relation to sustainable construction is, therefore, critical to wide industry transition from conventional to sustainable construction practices.

This paper investigates the general awareness of construction contractors with regards to environmental aspect of sustainable development; it also seeks to investigate the awareness and understanding towards social and economic aspects of sustainability amongst construction contractors in the state of Victoria, Australia. The literature review conducted below investigates current knowledge in these areas with focus on past research and the most current state of thinking. While the findings are used to identify areas where the scope of research can be expanded or extended to contractors in the Australian construction industry.

\section{Sustainable Development, Sustainability AND CONSTRUCTION}

Sustainable development and sustainable construction are intertwined. In order to understand sustainable construction there is a need to develop an understanding for sustainable development. The definitions for sustainable development are abundant in scope and term. According to reference [1], "Sustainable development is development that meets the needs of the present without compromising the ability of future generation to meet their own needs". According to reference [2], sustainable development is all about ensuring a better quality of life for everyone, now and for generation to come. Sustainable development and construction responsiveness and awareness are escalating around the world. 'Agenda 21', introduced in 1992 by the UN summit on environment and development, was the stepping stone of realisation by world leaders and scholars that the environment must be protected for future occupants through the concept of sustainable development [3], [4].

Reference [5] suggests that in recent years, the term sustainability has been widely adopted by both the public and private sectors. According to reference [6], the coverage of sustainable development have reached the mainstream public arena, in the local, national and on a global level. These terms are now in common use in scientific papers, monographs, textbooks, annual report of companies, government policy usage, and the media [7]. In fact, it is so overused that it has 
given birth to new lexicons, with words such as green washing, green supply chain management, green buildings, etc. becoming commonplace and gaining currency to describe the many attempts to co-opt the issue [8]. According to reference [5], given sustainability's broad meaning, it has been subjected to a range of interpretations. They further suggest that the different definitions of sustainable development imply that application of the term depends on their designation and recognition in different disciplines [5]. Considering the above reference [7], suggested that regardless of the discipline sustainable development should be supported by common, unambiguous, fundamental concepts applicable to real world problems [5]. The concept of sustainability is broad and has been used in different context, but the economic, social and environmental aspects, which are inextricably linked, remain the three fundamental pillars that must always be appropriately addressed [9]-[12]; and [5]. According to reference [5], the construction industry has often explored the economic dimension which explains why most of the times projects are awarded to the contractor with the lowest tender [13]. In the past, tenders used to be based solely on economic factors which measure short-term returns at the detriment of social and environmental issues which consider long-term benefits of an asset [14]. Thus there is a need to examine ways of incorporating other factors which have not always been considered in the past [5]. Using this holistic approach to select the best option among alternatives at an early stage of a development is vital in promoting sustainable practices in construction [15]-[18] and achieving this will mean looking for a way of measuring these three pillars of sustainability in monetary terms when proposing a new development or retrofitting the existing stock. [5]

The growing concerns of the impact that buildings have on the environment in Australia have eventually raised the awareness of the construction industry to implement sustainable practices into the construction process. With the view that implementation of sustainability measures in construction will as such drive sustainable construction in Australia. Sustainable construction is generally described as the application of sustainable development to the construction industry. [19] Refers sustainable construction as "the creation and responsible management of a healthy built environment based on resource efficient and ecological principles".

The construction industry involves a vast amount of stakeholders and these stakeholders are usually referred to as those who produce, develop, plan, design, build, alter and maintain the built environment. Building material suppliers, manufacturers, clients, end users and occupiers are examples of stakeholders that are involved in the construction industry. Considering the above and according to Reference [20], it is thus apparent that sustainable construction can be best described as a subset of sustainable development, which encircles matters such as tendering, site planning and organisation, material selection, recycling, and waste minimisation.

The construction industry makes many positive contributions to society, but it also has negative impacts on the environment. These include soil erosion, sedimentation, flash floods, destruction of vegetation, dust pollution, depletion of natural resources and the use of building materials that can be harmful to human health [21], [22]. While these findings demonstrate the significant adverse impact that the construction industry has on the environment, they also reflected the traditional focus on cost control, time and quality over environmental and social performance. The realisation of these impacts has led to the growth of studies on solutions for practicing sustainable construction across a project life cycle [23]. However, the effectiveness of sustainable construction methods has been limited in practice. This limitation is partly due to the profit driven culture in the industry; where cost, quality and scheduling have been the determinants ensuring maximum benefits to the construction firms. Reference [24] outlines a number of sustainable principals concerning the construction industry. These include:

1) Showing concern for people by ensuring they live in a healthy, safe and productive built environment in harmony with nature.

2) Safeguarding the interests of future generations while at the same time, meeting today's needs.

3) Evaluating the benefits and costs of the project to society and environment.

4) Minimising damage to the environment and its resources.

5) Improving the quality of buildings and services and promoting social cohesiveness.

6) Using technology and expert knowledge to seek information and in improving project efficiency and effectiveness.

Widespread agreement on sustainable construction does not necessarily result in extensive implementation of its practices. Although many construction practitioners agree with sustainability principles, many are yet to grasp their meaning and fewer have translated sustainability into action [25], [26].

One of the aspects within environmental sustainability is waste minimization. In 2004-05, construction and demolition (C\&D) waste generation in Australia totaled 15.1 million tons of which 7.5 million tonnes was residual waste to landfill [27]. In 2006-2007 the C\&D waste stream accounted for $38 \%$ of total waste, amounting to approximately 16.6 million tonnes [28]. In 2008-2009 C\&D waste generation in Australia increased to a total of 19.0 million tones of which 8.5 million tones was disposed to landfill while 10.5 million tones or 55\% was recovered and recycled [29]. In Victoria in 2008-2009 a total of 3.15 million tones of C\&D material was recovered for reprocessing, however, $47 \%$ of waste to landfill was generated from the C\&D sector [30].

Due to growing global concerns of the issues of sustainability, the government and the construction industry in Australia have taken innovative sustainable initiatives to encourage sustainable construction and development within Australia. Through these sustainable practices, positive outcomes are being realised by building occupiers, users and various stakeholders. Hence, the implementation of sustainable elements in construction is resulting into sustainable development and awareness by different construction participants.

The basic aim of the paper is to investigate the level of 
awareness regarding the sustainable construction by construction contractors and examine awareness and perceptions towards these factors from contractors' point of view as well as the implication for the contractors. The literature review revealed that there exisits limited awareness of the social aspects of sustainability, while the authors' believes that sustainability is commonly associated with 'financial loss for environmental gain'. The research question seeks to examine the accuracy of this hypothesis and make recommendations to the construction industry and academia based on the findings of the paper.

\section{RESEARCH METHODOLOGY}

For the purpose of obtaining necessary information, the methodology for this paper employed survey based investigation techniques employing Likert scales which are more suited to gaining insight in the perceptions and attitudes of the respondents. The research was carried out in two stages, in the first stage the focus was on the environmental aspects while in the second stage the focus was on the social and economic aspects of sustainable construction. The questions were developed through the extensive literature review and authors experience within the industry. The questionnaires focus on environmental, social and economic aspects of sustainability and asks participants to either rate their opinions on a scale from "strongly disagree" to "strongly agree" or rate the extent to which they utilise various sustainable practices from "never" to "always", based on question presented using a five-point Likert Scale. The aim was to examine awareness and understandings of construction contractors towards environmental, social and economic aspects of sustainable construction. Conclusions are based on how respondents responded regarding environmental, social and economic merits of sustainable construction and the extent to which these aspects influence decision making within construction contractor firms. By measuring current attitudes and awareness, recommendations are made.

A total of 150 questionnaires were distributed amongst project and site managers working for contractors in greater Melbourne area in the state of Victoria, Australia. Of these, 55 were filled in and returned. Respondents represent a diverse range of age, experience in industry, gender and sectors of the firms. Around half of the respondents have more than 10 years of experience within the construction industry. The main reason to survey site managers from contracting organisations was to get the realistic picture about efforts done in order to introduce sustainable practices within the construction projects. Contractors are the one who manage the construction sites. Despite processes in place and design being modified to take sustainability aspects into account, it is the site managers of contracting organisations who implement these efforts on the actual construction site. Therefore, their role in the whole process is quite crucial and it was important to survey to capture their perceptions.

\section{UNITS FINDINGS, DisCUSSION AND ANALYSIS}

The first stage investigated the general understanding and perception of contractors regarding the environmental aspect of sustainable development. Below are some of the questions with discussion and analysis.

The responders were asked regarding their perception of the biggest driver of sustainable development. In contractors perception the financial incentives and availability of green materials are the biggest drivers. On the other hand, government policies have been rarely considered in sustainable developments. Although sustainability initiates from the design stage, builders are pushed to utilize green materials in their development stages despite the availability. Building a sustainable development is expensive and for builders to make use of green materials, financial incentives must be granted. Such example includes the insulation rebate to encourage insulation companies to not only promote their business however to market the free insulation rebate from the government.

Regarding the importance of the sustainable development, a unanimous response was received from all the respondents who agreed that by incorporating sustainability into their mission statement, it provides them with a goal to achieve. Some contractors declared that if society fails to reduce greenhouse emissions, it will lead the environment to acceleration of climate change. Although Victoria has its own regulation ('all new homes will be required to meet the new 5 star standard'), the companies will need to accept these regulations as well as incorporating its significance into the company itself to enable the environment to advance to a "greener" future.

The respondents were also asked whether there were projects in which the sustainable construction initiatives have been overlooked due to cost. $75 \%$ of contractors responded that sustainable initiatives have been argued upon the bases of costs involved; as such they could not add any further sustainable initiatives due to cost constraints. From the data obtained, it is assumed that the other $25 \%$ did not give much weight to the costs involved in undertaking sustainable construction but rather their focus was the impact on the environment.

The respondents were questioned regarding their incorporating sustainable initiatives. It was unanimously reported that they have incorporated sustainability initiatives into their past projects. Many contractors perceive that by complying with the legislation can offer significant reductions in costs while at the same time significantly improving the negative effects on the environment and amenity/comfort of any facility. The respondents were also asked about their determination and commitment to incorporate sustainable initiatives into their future projects and developments. $50 \%$ stated that they would implement sustainable initiatives into future developments, while $50 \%$ stated that they did not know, or were unsure whether they will be able to commit.

The perception of the respondents about whether the government intervention and mandate should be implemented in Australia in regards to sustainable buildings was also investigated. The response was mixed as 50\% stated in favour of government intervention and mandate while $50 \%$ stated they were unsure. The respondents were also asked whether the government incentives provide a good 
reason for the respondents to invest in sustainable initiatives. All respondents stated that they believed government incentive provided a good reason for them to invest in sustainable initiatives in partnership with their clients.

The availability of sustainable material in the market was also investigated, $25 \%$ of the respondents stated that sustainable materials were readily available in the market, while $75 \%$ stated they were not. A few respondents commented that they were too expensive as compared to other countries. This shows that Australia may be lagging in sustainable construction due to cost of materials needed to implement these sustainable green practices.

The perception of the respondents about the return on investment of sustainable construction compared to conventional construction revealed that $75 \%$ of the respondents believed that sustainable construction provides a good return as compared to conventional buildings while $25 \%$ said they did not. This could be due to many reasons, such as experience in the field, skill set to make such informed decisions, location, personal experiences and personal ownership status.

The mechanism that was in place in the companies to capture good practice/lessons learnt and the process of the feedback to subsequent projects was also investigated. It was reported that that majority in the construction industry (50\%) have not got any sort of mechanism in place in their firms to capture good practice standards due to the time limitation and financial constraints they face in their business.

Based on the responses from the respondents obtained through the first stage, it is evident that there are many reasons for the underlying low level of sustainable development and sustainable construction within Australia. The following briefly describes the elements that drive and the barriers that impede the growth of sustainable development and sustainable construction within Australia.

\section{A. Drivers of Sustainable Development and Construction}

Through the findings, the authors have identified that the drivers of sustainable development and sustainable construction vary between different contractors in the industry within Greater Melbourne are of the State of Victoria, Australia. The prime reason is because of the different sectors and areas that the contractors deal in, for instance contractors who deals with the construction process of the sustainable construction believes that green material availability and availability of financial incentives are two factors that will increase the total volume of sustainable construction within Australia. Other drivers that were discussed which are believed to be significant aspects of sustainable development and sustainable construction includes government policy, environmental awareness, stakeholder preference, social issues and financial savings.

\section{B. Barriers of Sustainable Development and Construction}

The analysis of the result portrays that the main barrier of sustainable development and sustainable construction is the high cost that is involved in the whole construction process as well as the lack of government financial incentives and rebates. Other barriers that all the contractors believed that hinders the increase of sustainable construction and development within Australia includes the limited knowledge about the term sustainability, lack of general sustainability awareness, insufficient green materials in the market and low demand of sustainable development. Apart from the above drivers and barriers findings, the research study also found that limited sustainable initiatives have been implemented by the different industry stakeholders in today's construction of buildings. This is purely due to the overall reasonable awareness and know-how of the issue of sustainability in the development and construction sector as well. As such, there is a need to provide a more in-depth education and training for industry stakeholders in general in relation to the fundamentals of sustainability in construction. The researchers perceive that with the increase of education, training and understanding of the issue of sustainability within the key stakeholders in the industry, it will eventually enhance the integration of sustainable practices in the future construction and development.

The findings from second stage indicates overall positive attitudes and perceptions towards the social and economic aspects of sustainable construction. Attitudes towards the social aspects of sustainable construction were slightly more positive than attitudes towards economic aspects. This contradicts claims in the literature review that there is little awareness of social aspects due to difficulty in measuring them. However, the 'guilt factor' may have influenced respondents into ranking social benefits of sustainability higher than economic benefits.

Respondents with fewer years of experience in the construction industry demonstrated more positive perceptions towards social and economic benefits to sustainable construction. A large portion $(68 \%)$ of more experienced contractors were either impartial or hold negative/dismissive attitudes. Cultural changes and a higher emphasis on sustainability in the education system over the last decade may explain these findings. In the following sections, some of the questions are presented along with their response and analysis from the authors.

Results show $56 \%$ of contractors surveyed agree that sustainability is an important factor in the selection of sub-contractors and other supply chain participants which is positive feedback, however although that is a strong percentage there is room for improvement throughout the industry. This figure is showing a positive attitude towards sustainability and, although it is the supply chain of the construction process, it can be argued that this is extremely effective. It is a direct and effective way for builders / project managers to make a substantial difference in their sub-contractors on-site actions and forces a positive change in their behaviour \& culture in regards to sustainability. $27 \%$ deemed themselves to be 'neutral' while $16 \%$ disagreed or strongly disagreed. This may be due to their lack of knowledge \& awareness on sustainability or possibly their company does not have a stance on the issue. This demonstrates room further education within the industry on sustainability and sustainable practises.

Incorporating sustainability into all aspects of the design process lays the foundations for all stake holders \& contractors involved from the beginning. This is the most proficient and effective way of outlaying sustainable 
principles \& practises throughout the project because it captures everything from the beginning and creates a standard of the expectations for all involved. From a construction point of view, it makes easier incorporation of sustainable features in the proposed building as well as assisting waste management, recycling of materials, etc. $43 \%$ of respondents agreed that they incorporate sustainability in all aspects of the design process, this is a substantial figure although there is still opportunity for improvement in the industry.

From the results to this question, 'Your company would sacrifice profit to achieve wider social \& economic sustainability objectives'; it is evident that in Australia, particularly Victoria, contractors are not willing to sacrifice profit to achieve wider social and economic sustainability objectives (see Fig. 1). Given the answers to another question, that the clients are not willing to pay premium prices for sustainable practices, it falls back on the contractor to make this sacrifice to their profit in order to achieve sustainable construction. With the contractors being hesitant to make this sacrifice, government policy is necessary to drive sustainable construction.

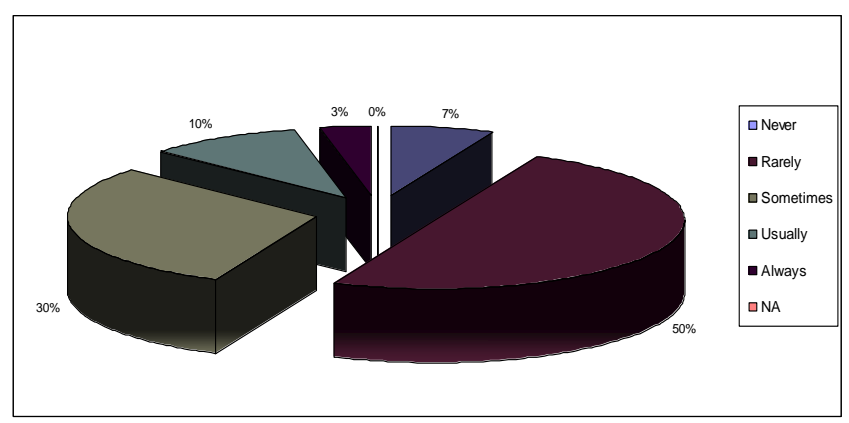

Fig. 1. Question 4 - Your company would sacrifice profit to achieve wider social \& economic sustainability objectives.

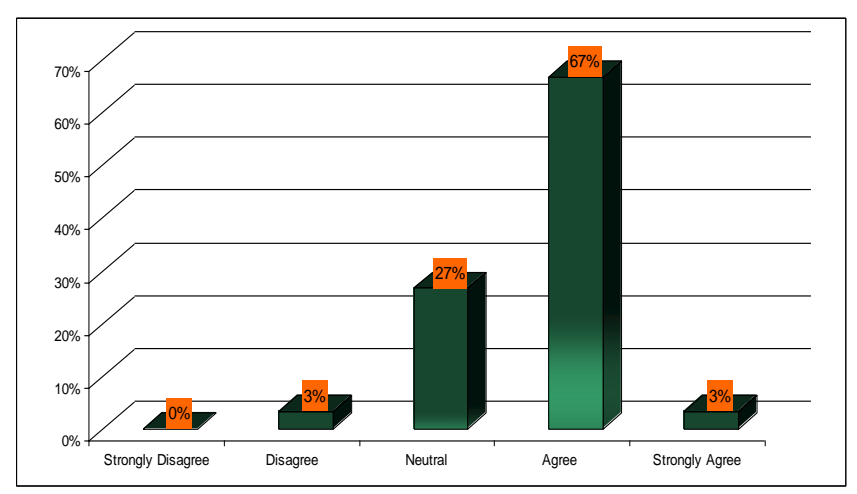

Fig. 2. Question 5 - Sustainable buildings have a reduced life cycle cost.

These results suggest some consensus amongst contractors that sustainable buildings do in fact have a reduced life cycle cost when compared to similar but non sustainable buildings (see Fig. 2). Zero respondents stated they strongly disagreed and only $3 \%$ disagreed and thought that sustainable buildings had higher life cycle costs than non-sustainable buildings. $70 \%$ of those surveyed either agreed or strongly agreed. These responses are consistent with the findings of a 2003 study conducted by [31] into the life cycle cost of sustainable commercial buildings. The challenge for the contractor is to communicate these long term financial benefits to the client in order to encourage short term financial sacrifice for long term economic gain.

The statement. 'We help employees and sub-contractors to update and acquire new skills', gauged the contractors opinions of themselves and whether or not they, as a company, help and encourage their employees or sub-contractors and supply chain partners to further their education and keep updated with acquiring new skills required for the job. $63 \%$ of respondents feel that they did assist employees with acquired new skills and continuing their professional development in the industry. $20 \%$ of contractors surveyed returned a negative reply, these contractors believing that they were not doing enough in helping employees learn new skills. The fact that they recognise this problem is somewhat encouraging. Reference [25] recognises employee development as a social aspect of sustainability.

The use of local sub-contractors and suppliers can also be more environmentally sustainable than non-local ones. Non-local labour and materials implies the need for extra transportation with causes excess emissions. This can be seen clearly in Reference [32] which stated that the use of local materials in their case study reduced the impact of transportation by $53 \% .80 \%$ of responses to this question said they 'usually' or 'always' involve local sub-contractors and suppliers on their projects. There were zero response for both 'rarely' and 'never'. This is again a very positive result which demonstrates that construction contractors are using local sub-contractors and suppliers in their projects. The use of local sub-contractors and suppliers promotes local economic growth and provides construction organisations with other economic benefits such as improved public image and relations.

Our literature review reveals that the use of local materials in a project can significantly reduce emissions mainly due to the reduction in transport. Using local materials also ensures that materials are coming from sustainable sources that utilize proper extraction methods as opposed to international materials that may have less strict guidelines and therefore may be cheaper. Further research is required to discover whether or not the local suppliers being utilised by contractors are indeed using local materials. Data would also need to be gathered on whether or not local materials are being used would affect the decision making of contractors when selecting a supplier for a project.

The results of question 10 show that almost all contractors aim to create local jobs on projects 'usually' or 'always'. Only 1 contractor responded that they 'rarely' try to do so. The results of question 11 show an almost perfectly even spread of data. It is difficult to draw conclusions from this data and therefore further research from a larger sample pool is required. Overall the results of these two questions suggest that the majority of construction contractors do have an awareness of economic sustainability and do have a positive attitude towards it. It also shows that there is plenty of room for improvement as there were still a large proportion of 'sometimes' and 'rarely'. Community development is typically seen as the responsibility of the government which may lead to some organisations rarely actively contributing towards it. 
Education of the benefits of creating local jobs and trainee positions such as business development and public image should be portrayed to those contractors that rarely or sometimes aim to contribute towards economic development. Further research is needed to understand why contractors would not always aim to create local jobs and trainee positions on projects so that the trend can be reversed.

These results indicate that the majority of organisations from which the surveyed contractors are from do have equality and diversity policies in place which shows awareness and a positive attitude towards social sustainability. The research from our literature review showed that social aspects of sustainability are often ignored so this result is somewhat surprising. The fact that Australia is such a diverse country and has much stricter laws regarding to social equality than other countries may explain why our results differ from our research gathered from international journals.

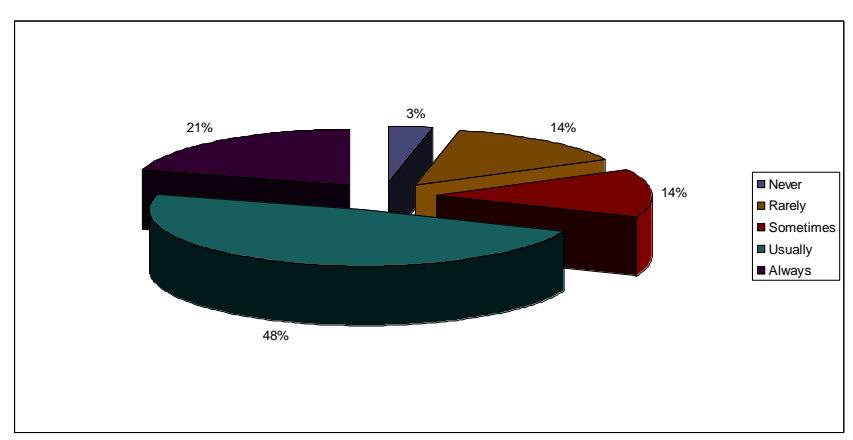

Fig. 3. Question 12 - We have equality and diversity policies in place, which is also translated on our on-going projects.

\section{CONCLUSION}

While the results indicate that social policies are common in the construction organisations surveyed it is unclear how they are maintained or if they are maintained at all. Further research would be required to better understand how these policies are policed and how they impact on other aspects of social sustainability such as job security and job satisfaction.

The study found an overall positive attitude and fairly high level of awareness towards the social and economic aspects of sustainable construction. The majority of respondent agreed to statements that favourer social and economic aspects of sustainable construction, while also claiming that they usually utilise these practices.

Respondents demonstrated positive attitudes to the use of recycled materials and effective waste management. They recognised the cost effectiveness of using locally sources labour, and claimed commitment to the practice. Life cycle cost benefits of sustainable design were recognised and respondents claimed that sustainable practices improve their competitiveness. The majority of respondents also claimed that they have adequate knowledge in sustainable construction, that they are active in education employees and sub-contractors and that they are committed to sustainability. The majority of these areas of sustainability have positive financial implications to the contractors, which may explain the high level of awareness and positive attitudes towards these aspects. These finding may imply that free market forces are a strong driver to a broader shift to sustainable construction.

Particular areas of poor performance include workers attitudes towards sustainable construction, the incorporation of sustainability in the design phase, and the willingness of clients to pay premium price to implement sustainable practices. A possible explanation for these results is a lack of education amongst both clients and workers in regarding sustainability. These factors pose significant challenges to the future of sustainable construction within Australia and can only be mitigated through broader education.

From the observation from this pilot study and our literature review, our research team can make the following recommendations.

Higher education sector should take greater measures to educate workers and sub-contractors about sustainable construction practices. As workers and subcontractors rarely have a share in the cost saving aspect of sustainability, contractors should provide extra incentive for workers to actively seek these practices.

While the surveys reveal significant financial benefits of sustainable design to the end user, responses reveal a lack in client demand for sustainable buildings. Contractors should take measures to improve client awareness of these benefits which should also be advocated in the higher education system and through government campaigns. It is also important to obtain sustainable design prior to the commencement of the construction in order to create green buildings. Sustainable design assists in making the right construction solutions, for instance in terms of materials selection, building orientation, costs and lighting system. In order to identify the building performance of buildings in Australia, an array of building assessment tools have been developed in Australia.

Responses also indicate a lack in incorporation of sustainability in the design phase. Past research reveals that early incorporation of sustainability is the deciding factor in construction cost. This has significant bottom line profit implications for contractors who should take greater measures to ensure early incorporation of sustainability.

It is clear that sustainable construction is a vital aspect when creating sustainable development. As such, cyclical construction lifecycle should be adopted instead of the traditional linear construction process. The triple bottom line which involves the social, environmental and economic factors are fundamental issues that needs to be identified and incorporated in sustainable construction to ensure that a sustainable development is formed. Sustainable development and green building provides a large amount of benefits as it has minimal environmental impact, enhances indoor environment quality to improve the well-being as well as productivity of the occupants and it also allows for great financial savings. Due to its many advantages, Australia should as such further increase its awareness and concern of the incorporation of sustainability practices in conventional construction.

Besides that, it is also important to obtain sustainable design prior to the commencement of the construction in order to create green buildings. Sustainable design assists in making the right construction solutions, for instance in terms 
of materials selection, building orientation, costs and lighting system. In order to identify the building performance of buildings in Australia, an array of building assessment tools have been developed in Australia based on UK's BREEAM methodology. This building assessment system provides the stakeholders and building occupiers with an analysis of the building characteristics and performance. In addition to environmental aspect, social and economic aspects of sustainability as discussed in this paper should not be ignored.

Hence, sustainable practices must be adopted by stakeholders within the construction industry to ensure that more sustainable development is achieved in the future. The Australian Government must play its part and move towards the realization that sustainable issues are not just a notional debateable issue, but a minimum standard of living for every Australian in the public, private and community sector. Development Agencies, sole developers, builders, subcontractors, designers, architects, clients and many more in the whole construction industry must be rewarded through fiscal and economic policy for implementing sustainable policies and initiatives in construction, development, refurbishment and design.

According to the responses provided, the majority of the contractors are aware of the issue of the triple bottom line (social, environmental and economical), sustainable development is still regularly neglected in Australia due to the involvement of high construction cost and the lack of readily available green material in the market. Hence, in the future, when there is an increase of green materials in the Australian market together with the availability of government incentives as well as rebate, the construction cost will be reduced. These factors will ultimately boost sustainable construction and sustainable development in the near future in Australia.

\section{REFERENCES}

[1] G. H. Brundtland and W. C. O. Environment, Development, Oxford University Press Oxford, Our common future, vol. 383, 1987.

[2] H. Bossel, "Indicators for sustainable development: Theory, method," Applications: International Institute for Sustainable Development Winnipeg, 1999.

[3] S. Parkin, "Contexts and drivers for operationalizing sustainable development," in Proc. the ICE-Civil Engineering, 2000, pp. 9-15.

[4] S. Parkin, "Sustainable development: the concept and the practical challenge," in Proc. the ICE-Civil Engineering, 2000, pp. 3-8.

[5] D. Ekundayo, S. Perera, C. Udeaja, and L. Zhou, Achieving Economic and Environmental Sustainability through Optimum Balance of Costs, 2011.

[6] R. Barkemeyer, F. Figge, D. Holt, and B. Wettstein, "What the papers say: trends in sustainability, a comparative analysis of 115 leading national newspapers worldwide," Journal of Corporate Citizenship, vol. 2009, pp. 68-86, 2009.

[7] P. Glavič and R. Lukman, "Review of sustainability terms and their definitions," Journal of Cleaner Production, vol. 15, pp. 1875-1885, 2007.

[8] J. Mills, "The civics of sustainability: An overview," National Civic Review, vol. 99, pp. 3-6, 2010.

[9] G. Kunszt, "Sustainable development and the Hungarian construction industry," Building Research \& Information, vol. 26, pp. 46-55, 1998.

[10] G. K. Ding, "Developing a multicriteria approach for the measurement of sustainable performance," Building Research \& Information, vol. 33 pp. 3-16, 2005 .

[11] M. M. Matar, M. E. Georgy, and M. E. Ibrahim, "Sustainable construction management: introduction of the operational context space (OCS)," Construction Management and Economics, vol. 26, pp. $261-275,2008$
[12] T. Jones, Y. Shan, and P. M. Goodrum, “An investigation of corporate approaches to sustainability in the US engineering and construction industry," Construction Management and Economics, vol. 28, pp. 971-983, 2010.

[13] F. T. E. Fotwe and A. D. Price, "A social ontology for appraising sustainability of construction projects and developments," International Journal of Project Management, vol. 27, pp. 313-322, 2009.

[14] OGC, "Whole-life costing and cost management, office of government commerce," The Achieving Excellence Procurement Guides 07, London 2007.

[15] B. C. Lippiatt, "Selecting cost-effective green building products: BEES approach," Journal of Construction Engineering and Management, vol. 125, pp. 448-455, 1999.

[16] BERR, "Strategy for sustainable construction," London: Department for Business, Enterprise and Regulatory Reform, HM Government., 2008.

[17] R. Essa and C. Fortune, "Pre-construction evaluation practices of sustainable housing projects in the UK," Engineering Construction \& Architectural Management, vol. 15, pp. 514-526, 2008.

[18] M. Š. Zavrl, R. Žarnić, and J. Šelih, "Multicriterial sustainability assessment of residential buildings," Technological and Economic Development of Economy, vol. 15, pp. 612-630, 2009.

[19] PAC. (September 2009) Leed and Building Green, Protrend Arrow. Construction LEED. [Online]. Available: http://www.protrend-arrow.com/about/leed

[20] C. Langston and G. K. C. Ding, Sustainable Practices in the Built Environment, 2nd ed., Oxford: Butterworth-Heinemann, 2001.

[21] A. Klang, P.-Å. Vikman, and H. Brattebø, "Sustainable management of demolition waste - An integrated model for the evaluation of environmental, economic and social aspects," Resources, Conservation and Recycling, vol. 38, pp. 317-334, 2003.

[22] CIDB, "Malaysian Construction Industry Development Board," Annual Report 2007

[23] V. W. Y. Tam and K. N. Le, "Environmental assessment by power spectrum," in Joint International Conference on Construction Culture, Innovation, and Management, Dubai, 2006, pp. 395-403.

[24] N. Z. Abidin and C. L. Pasquire, "Delivering sustainability through value management: concept and performance overview," Engineering, Construction and Architectural Management, vol. 12, pp. 168-180, 2005.

[25] R. Ashley, D. Blackwood, D. Butler, and P. Jowitt, Sustainable Water Services, 2005

[26] M. M. Khalfan, "Managing sustainability within construction projects," Journal of Environmental Assessment Policy and Management, vol. 8, pp. 41-60, 2006

[27] W. M. Intelligence, "The blue book: Australian waste industry: 2007/08 industry and market report," WCS Market Intelligence, North Sydney, N.S.W, 2008.

[28] DSEWPC, "Construction and demolition waste guide - recycling and re-use across the supply chain," Commonwealth of Australia, Canberra 2011.

[29] H. Consulting, "Construction and demolition waste status report, Management of construction and demolition waste in Australia," Report prepared for the Department of Sustainability, Environment, Water, Population, Communities Queensland Department of Environment and Resource Management, 2011.

[30] S. Victoria, Towards Zero Waste Strategy Progress Report 2005- 2009, 2010.

[31] G. Kats, L. Alevantis, A. Berman, E. Mills, and J. Perlman, "The Costs and Financial Benefits of Green Buildings," A Report to California's Sustainable Building Task Force, United States Green Building Council. 2003

[32] J. Morel, A. Mesbah, M. Oggero, and P. Walker, "Building houses with local materials: means to drastically reduce the environmental impact of construction," Building and Environment, vol. 36, pp. 1119-1126, 2001.

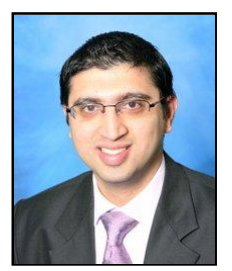

Malik Khalfan is an associate professor in School of Property, Construction and Project Management at RMIT University. Malik has a civil engineering degree from NED University, Karachi and masters in construction project management and $\mathrm{PhD}$ in construction management, both from Loughborough University, UK. Malik has worked as a site engineer in Karachi before embarking to his postgraduate studies. After completing his $\mathrm{PhD}$, Malik worked at Loughborough University as research associate. Then he moved on to take position at University of 
Salford as a research fellow and became a senior research fellow in 2008 . He joined RMIT in mid 2009 as a senior lecturer - contributing towards teaching, research and administrative activities in the School. Since his time at RMIT, Malik has collaborated with academic staff to conduct collaborative research, resulted in several research publications with A/Prof Tayyab Maqsood and a research project led by Prof. Kerry London and awarded by Sustainability Victoria. In addition to the above, Malik has collaborated with researchers from around the world towards joint publication and presently serving as the joint co-ordinator for CIB W102 Knowledge Management in Building working commission along with Prof Charles Egbu from Salford. Malik is also serving on the editorial board of many journals and served as scientific committee members for various conferences. Currently, he is also a member of AIB Victorian-chapter committee. Malik has also delivered various guest lectures as visiting fellow and presented his research work at number of conferences in last 14 years. Malik has also contributed in organising various conferences in the past as organising committee member. Malik is a co-editor of two conference proceedings, guest editor of three journal issues, and co-editor of an edited book (forthcoming).

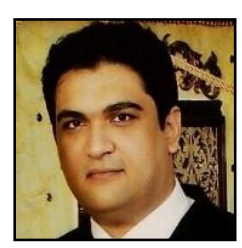

Muhammad Ali Noor is an assistant professor at the Institute of Management Studies, University of Peshawar. He is a graduate of civil engineering from NWFP University of Engineering and Technology Peshawar, Pakistan. He received his masters (MSc) in project and enterprise management from University College London (UCL), UK in addition to masters (MSc) in economics from University of Peshawar, Pakistan. He has a doctor of philosophy $(\mathrm{PhD})$ degree from Royal Melbourne Institute of Technology (RMIT), Australia. His doctoral research is on procurement of infrastructure projects in Pakistan. He has experience of working in public sector in Pakistan especially in infrastructure projects funded by the World Bank, Asian Development Bank and the United Nations in addition to projects funded by Government of Pakistan. Presently he is on deputation as the Director General Pakistan Planning and Management Institute the Ministry of Planning, Development and Reform Government of Pakistan.

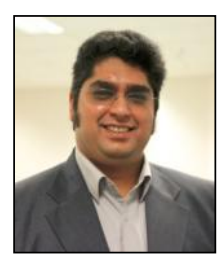

Tayyab Maqsood is currently working as an associate professor in project management and a deputy head of learning and teaching in the School of property, construction and project management at RMIT University. He leads a team of highly capable academics associated with the delivery of undergraduate and postgraduate programs in construction, project management and property disciplines. He graduated as a civil engineer in 1995 and obtained a master of engineering degree in construction engineering and management in 1999 where he was awarded a prestigious Mahesh Verma award. He has worked in Hong Kong, UK, Thailand, and Pakistan in various capacities as lecturer, project engineer and research associate before settling in Australia in 2002. He earned his $\mathrm{PhD}$ in the area of project management from RMIT University in 2006 specialising in knowledge management, organisational learning and innovation in construction industry. He is a recognised expert in this area and has widely published and presented internationally. He has authored/co-authored over 70 peer reviewed publications (conference papers, journal papers and book chapters). He lectures in both undergraduate and postgraduate degree programs in construction project management and teaches courses on project planning/control and project risk management. He has successfully supervised four $\mathrm{PhD}$ students for their doctoral degrees and is a senior supervisor for six $\mathrm{PhD}$ students who are currently undertaking their doctoral studies. He is a member of Institution of Engineers Australia and Project Management Institute.

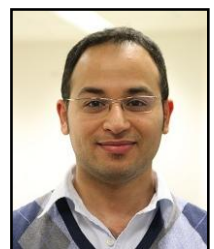

Nawaf M. Alshanbri is a PhD student at School of Property Construction and Project Management. The $\mathrm{PhD}$ research is about investigating the role of knowledge management and human resource management in assisting the employee's replacement process in Saudi Arabia.

Farshid Rahmani is a PhD student at School of Property Construction and Project Management. His PhD research looks at different procurement methods employed in Australian construction industry with emphasis on Early Contractors Involvement (ECI).

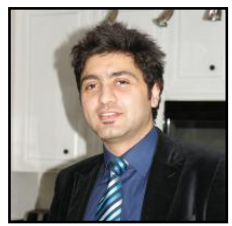

Amrit Sagoo is a senior lecturer at School of Property Construction and Project Management. $\mathrm{He}$ is also serving as program manager for project management programs both at undergraduate and postgraduate levels. 